\title{
Design of Nine Level Inverter Topology for Three Phase Induction Motor Drives
}

\author{
G. Sudhakar and S. Prabhakaran
}

\begin{abstract}
A new approach of nine levels cascaded $\mathrm{H}$ bridge multilevel inverter is proposed for three phase induction motor drives. Multilevel inverter is used synthesize a nearby sinusoidal voltage from various levels of $d c$ voltages and the proposed cascade $H$ bridge inverter is used to reduce the number of switches. The proposed nine level cascaded $\mathrm{H}$ bridge multilevel inverters require less number of components to obtain same number of voltage levels when compared to diode clamped and flying capacitor type methods. Due to that, the switching loss gets reduced as same like the harmonic distortion occurs in the motor drive gets reduced. Also, it generally regularizes the stair-case voltage waveform from several dc sources which has reduced harmonic content. The operational principle and key waveforms are analyzed and the performance of the proposed multilevel inverter is evaluated from the simulation results.
\end{abstract}

Keywords--- Induction Motor Drives, Multilevel Inverters, Switching Functions

\section{INTRODUCTION}

$\mathbf{M}$ ULTILEVEL inverter has become more famous over previous years in high power electric applications without the usage of a transformer and filters [1]. Multilevel inverters can be categorized into three topologies, they are, diode-clamped, flying-capacitor and cascaded H-bridge cell. The idea of cascaded multilevel inverter is based on linking Hbridge inverters in series to attain an output of sinusoidal voltage. The output voltage is the sum of the voltage that is produced by each cell. As the number of levels gets increases, the synthesized output waveform has several steps which generate a staircase wave that approaches a preferred waveform [2]. The inverter source voltage generate an output voltage or a current among certain levels either 0 or $\pm \mathrm{Vdc}$ is called as two-level inverter. Along with that, cascaded Hbridge multilevel inverters have been received an immense attention because of their qualities such as minimum number of components, reliability and modularity. In the point of view, attaining a sinusoidal output voltage wave, multilevel inverters may well increase the number of output voltage levels. Though, it will require more components resulted in complication and cost increase. To reduce these

G. Sudhakar, Post Graduate Student, The Kavery Engineering College, Salem, India.E-mail: pgsudhakar@gmail.com

S. Prabhakaran, Asst Professor, The Kavery Engineering College, Salem, disadvantages, multilevel inverter employing cascaded transformers.

Generally, there is neutral-point-clamped (NPC) inverter, the flying capacitor (FC) inverter, and the cascaded H-bridge (CHB) inverter, are the three converters which are presented is named as conventional multilevel converters. The three-level diode clamped approach is proposed by Nabae et al. This approach needs special modulation techniques to control the intrinsic fluctuations in voltages across the series connected capacitors and the resultant distortion in the output voltage. While this topological approach is scalable, the balancing of the capacitor voltages becomes complex at higher number of voltage levels. Furthermore, a considerable increase in the number of clamping diodes make this topology very intricate and less resourceful at higher number of voltage levels.

As the multilevel converter is broadly applied in the industries because the demand to operate switching, power converters in high power application has the growth constantly. The capacity of multilevel converters to operate at high voltages of the AC waveforms has low distortion, high quality and high efficiency. However, the multilevel converter [3] topology has improved efficiency by using various controls to attain high efficiency and increase to save energy. In this paper, the topology proposed is nine-level cascaded multilevel $\mathrm{H}$ bridge inverter for three phase induction motor. A nine level cascaded multilevel $\mathrm{H}$ bridge inverter to reduce the Total Harmonic Distortion (THD) [4] of the inverter output voltages for three-phase induction motor drive are presented.

\section{GenERALIZED H-BRIDGE CASCADED TOPOLOGY}

The fundamental H-Bridge cascaded topology is shown in the figure 1and the respective operational waveforms is shown in figure 2. For attaining a three level output a basic H-Bridge topology needs one DC source all along with four MOSFET switches and one balancing capacitors. In turn to get consequent levels necessitate a same set of topology as shown in figure 1 which increases the number of components required which in turn make design complexity and increases the cost and number of components used [5, 6].It is also to be establish that the maximum output voltage cannot go beyond the sum of voltage of individual sources which becomes the most important setback of this topology. For that reason in an application which requires high output voltage from low voltage level, it wants $\mathrm{H}$ bridge module in addition or step-up transformers. To triumph over this problem proposed a new configuration is shown in fig 3. India. 


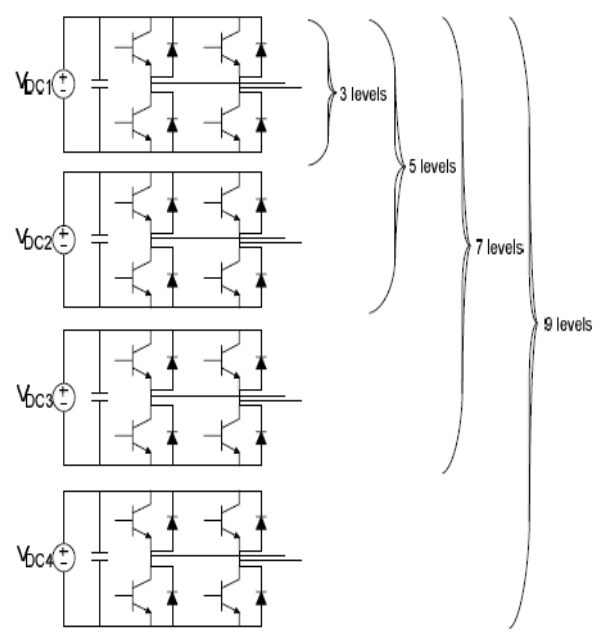

Figure 1: Traditional cascaded H-bridge cell multilevel inverter (nine levels)

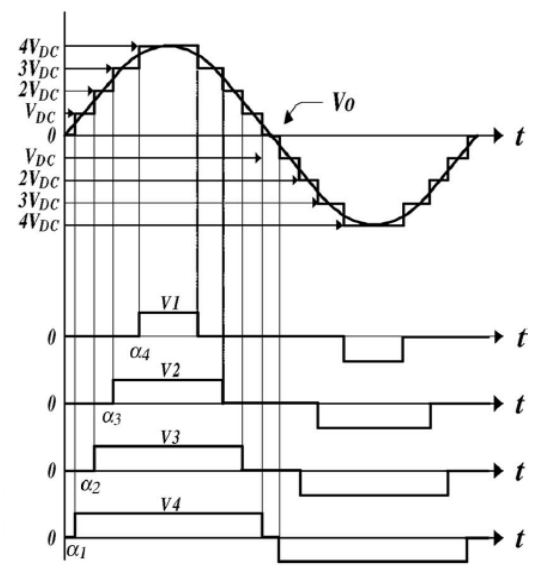

Figure 2: Operational Waveforms

\section{PROPOSED MULTILEVEL INVERTER}

Fig. 3 shows a circuit arrangement of a cascaded H-bridge multilevel inverter using trinary dc input source. It views like a conventional cascaded H-bridge multilevel inverter apart from input dc sources. By using $\mathrm{Vdc}$ and $3 \mathrm{Vdc}$, it can synthesize nine output levels; $-4 \mathrm{Vdc},-3 \mathrm{Vdc},-2 \mathrm{Vdc},-\mathrm{Vdc}, 0$, $\mathrm{Vdc}, 2 \mathrm{Vdc}, 3 \mathrm{Vdc}, 4 \mathrm{Vdc}$. Fig. 4 shows a fundamental design to generate output voltage levels. The lower inverter generates an elementary output voltage with three levels and then the upper inverter adds or subtracts one level from the fundamental wave to synthesize stepped waves. At this point, the final output voltage level becomes the sum of each terminal voltage of H-bridge [7, 8].

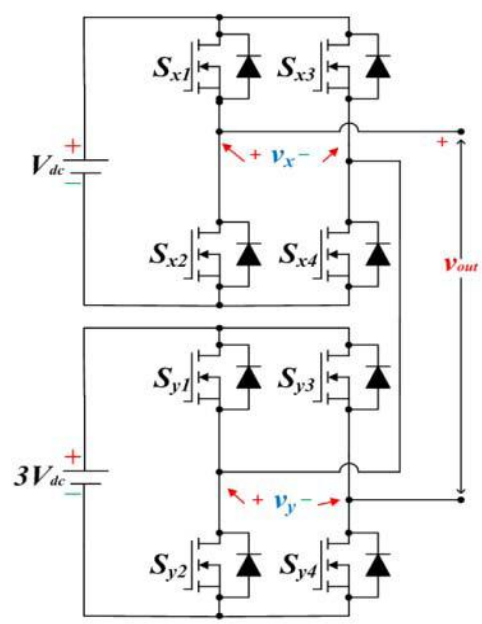

Figure 3: Cascaded H-bridge multilevel inverter using trinary dc sources

In the proposed circuit design, suppose the $n$ number of $\mathrm{H}$ bridge component has self-governing dc sources in sequence of the power of 3, a predictable output voltage level is given as

$$
V_{n}=3^{n}, n=1,2,3, . .
$$

Switching functions of the upper H-bridge inverter $\left(\boldsymbol{S}_{\boldsymbol{F B 1}}\right)$ and the lower H-bridge inverter $\left(\boldsymbol{S}_{\boldsymbol{F B} \boldsymbol{2}}\right)$ are expressed respectively.

To maintain zero level, $S x 2$ and $S x 4$ are turned on, whereas $S y 2$ and Sy4 are turned off. At theta 1, SxI and Sxy are turned on to produce $V d c$, and the lower inverter maintains zero level by turning on of $S y 2$ and $S y 4$. At theta 2, Sx2 and $S x 3$ are switched on to produce $-V d c$. At the same time, $S y l$ and $S y 4$ are turned on to generate $3 V d c$, then, vout becomes $2 V d c$. At theta 3, the upper inverter produces zero level by turning on of $S x 2$ and $S x 4$. To synthesize $3 V d c, S y 1$ and $S y 4$ are turned on. At theta 4, $S x l$ and $S x 4$ are turned on to make a $V d c$ level, and Syl and Sy 4 are turned on to produce $3 V d c$. Hence, vout becomes $4 V d c$. We can synthesize negative voltage levels by referring to Fig. 4(f)-(i)

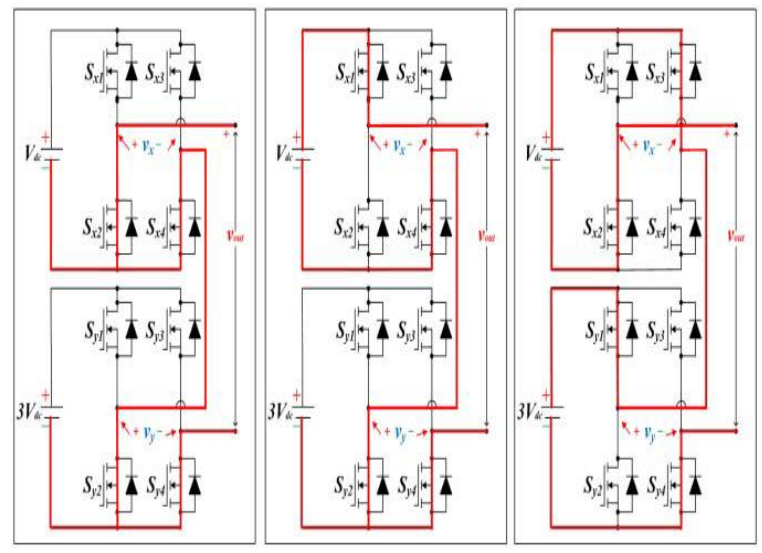

(a), (b) (c) 


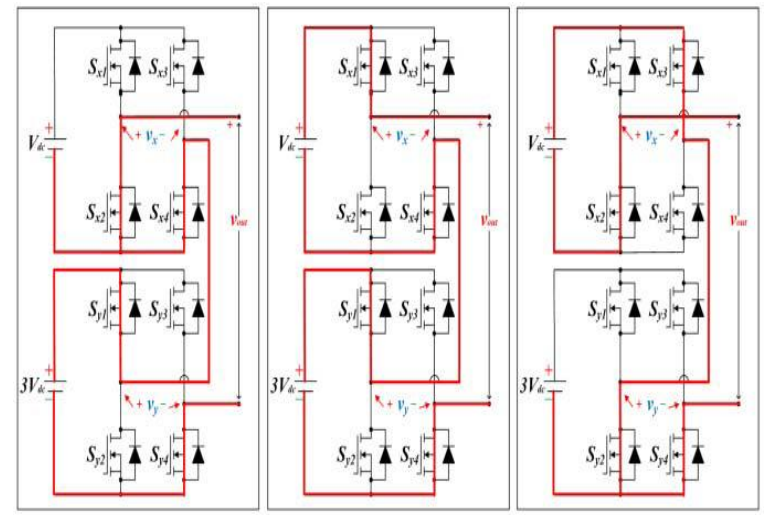

(d), (e), (f)

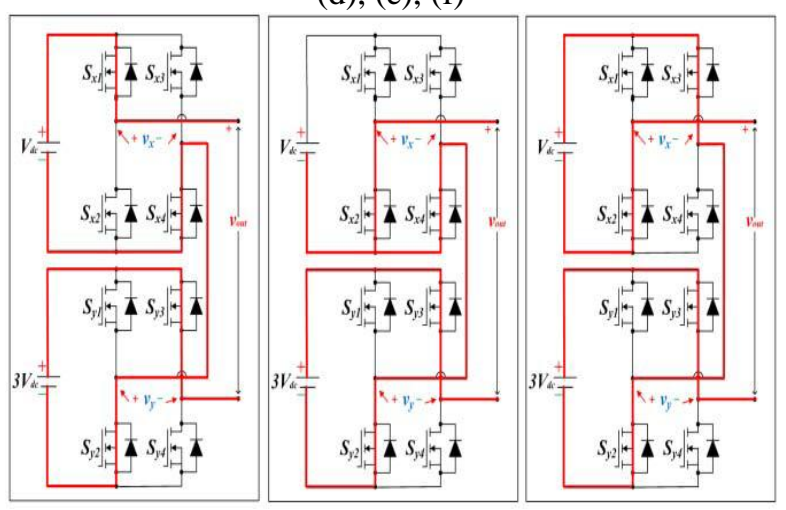

(g), (h), (i)

Figure 4:Operational mode to produce output voltage levels, (a) 0-level, (b) $V d c$, (c) $2 V d c$, (d) $3 V d c$, (e) $4 V d c$, (f) $-V d c$, (g) $-2 V d c$, (h) $-3 V d c$, (i) $-4 V d c$.

Waveforms of output voltage are denoted as (vout), upper terminal voltage is $(v x)$ and the lower voltage is $(v y)$ inverter in sequence. The output voltage has nine levels include zero level. Though it is close to a sinusoidal wave, it has lower order harmonics. So it needs more H-bridge modules or output filter to obtain high quality output voltages. Advantage of the proposed multilevel inverter scheme is the elimination of transformer in the main power stage. However, each cell of the proposed multilevel inverter requires its own isolated power supply. The provision of these isolated supplies is the main limitation in the power electronic circuit design. So the proposed multilevel inverter is suitable for photovoltaic power generating systems equipped with distributed power sources $[9,10]$.

\section{SimUlation AND EXPERIMENTAL RESUlTS}

The experiment is conducted in MATLAB. The simulation of the proposed multilevel inverter was implemented by using MATLAB.

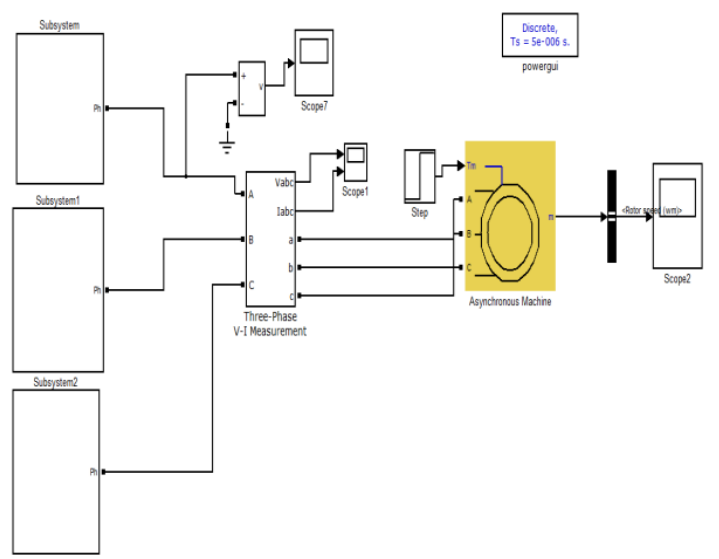

Figure 5: Simulation representation of Nine Level Inverter

The simulation circuit of the proposed inverter is designed using eight MOSFET switches for producing nine levels is shown in figure 5 . The gate pulse of the circuit is generated by PWM technique. The pulse is generated using comparison between constant DC voltage and power supply. The comparison is done using operational amplifiers. For the initial pulse a DC voltage of smaller amplitude is given and sensible amplitude is given for the second pulse. Similarly, to increase the amplitude of the system, pulse width is to be reduced. The PWM technique is used to attain a fine harmonic spectrum. The supply is given through three separate DC sources. The Motor load is used for the simulation purpose. The simulation results show that the circuit the proposed approach functions properly. The output waveform contains nine levels in which four levels in the positive side and four levels in the negative side and a zero level. Thus the proposed multilevel inverter for nine levels is successfully simulated.

The output voltage of nine level inverter performance of the proposed modified cascaded multilevel inverter for induction motor drive is verified through the simulation results. Input voltages for each succeeding voltage source are alike. The simulation diagram of three phase modified cascaded multilevel inverter for induction motor drive. From that multilevel inverter nine levels can be simply attain by producing the sequence of switching pulses. The output voltage waveform of three phase line to ground and line to line voltages of the proposed inverter is derived for induction motor. The speed and torque cures are derived for induction motor to predict the performance of the proposed system is shown in the figure 7 and 8 . From the speed and torque curves, it is noted that the targeted speed is achieved early as same like the torque value is also achieved. Therefore the proposed multilevel inverter can be used for variable speed drive application, which can be obtained by varying the frequency of multilevel inverter. 


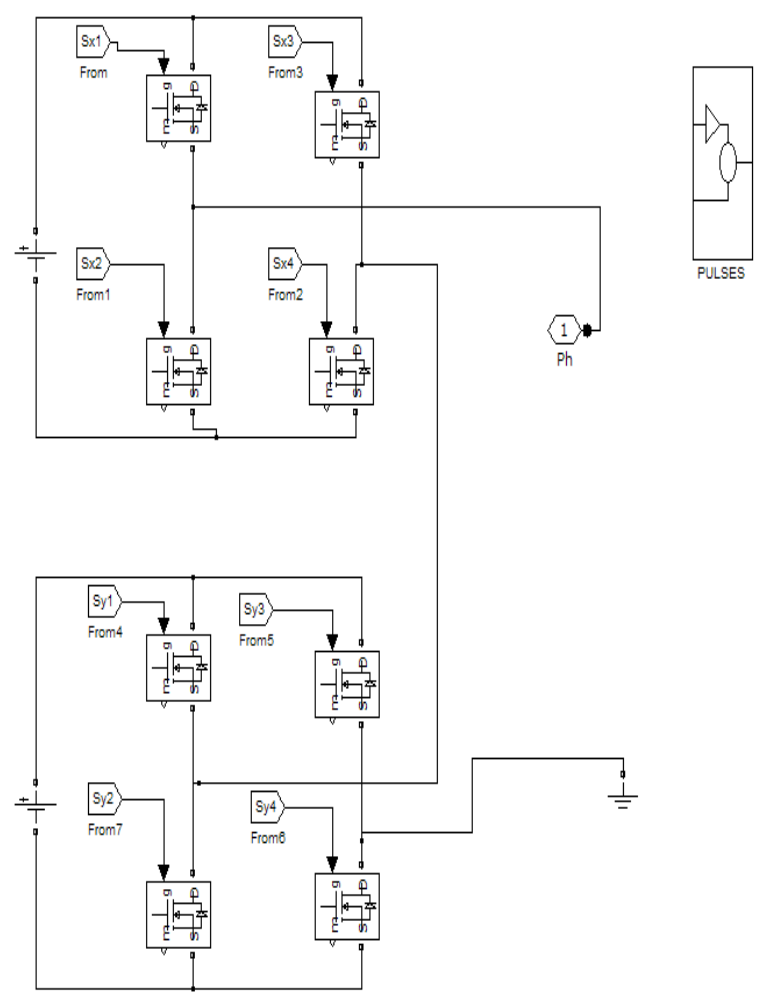

Figure 6: Sub System design for Nine Level Inverter

The MOSFET and internal diode are in parallel with a series RC snubber circuit. When a gate signal is applied to the MOSFET, it conducts and acts as resistance in both directions. If the gate signal falls to zero, when current is negative. Continuously gate pulses given to the MOSFET stepped waveforms are produced at output voltage side. The different modes of operation execute voltage depending upon PWM technique.

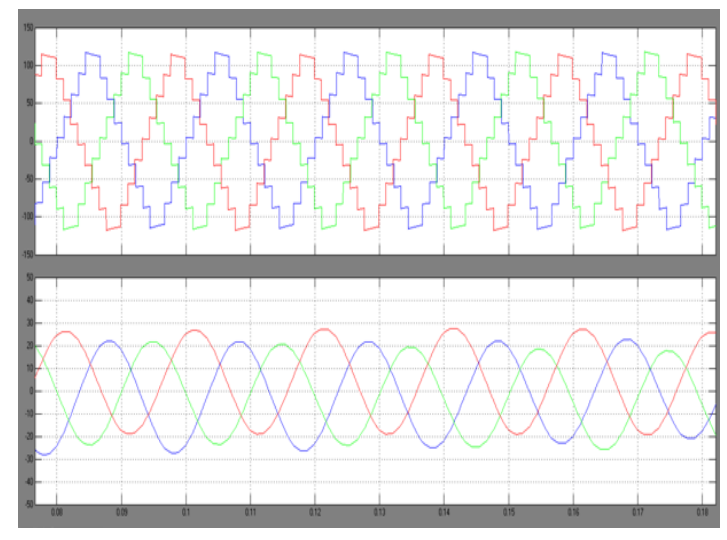

Figure 7: Simulation Result for voltage and current

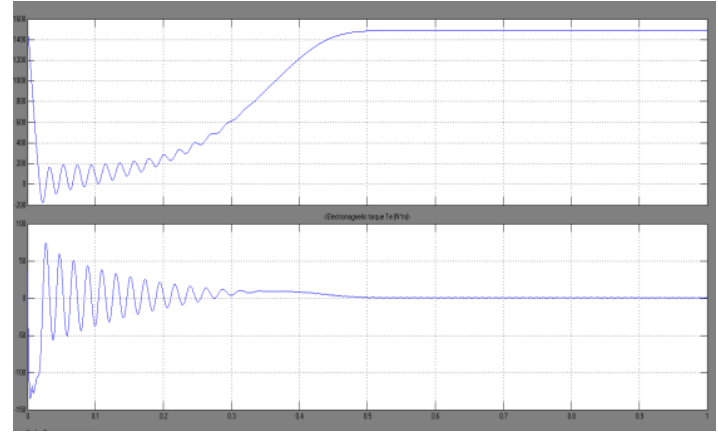

Figure 8: Simulation Result for Rotor Speed and Motor Torque

\section{CONCLUSION}

In this paper, proposed a cascaded H-bridge multilevel inverter for three phase induction motor drive which makes use of trinary dc sources to achieve a large number of output voltage levels with minimum number of switching devices. The proposed inverter can produce high quality output voltage close to sinusoidal waves. The circuit arrangement is troublefree and easy to control. The operational principle and key waveforms are illustrated and analyzed. Valuable and presentable merits of the proposed approach are summarized as

(1) Economical circuit configuration to produce multilevel outputs by means of trinary input sources,

(2) Easy to increase of the output voltage levels and output power owing to modularity characteristic.

\section{REFERENCES}

[1] Bailu Xiao and Faete Filho "Single-Phase Cascaded H-Bridge Multilevel Inverter with Non active Power Compensation for GridConnected Photovoltaic Generators" IJERA 2010.

[2] Rokan Ali Ahmed and S.Mekhilef "New multilevel inverter topology with reduced number of switches" IMEPCON 2010

[3] P. P. Rajeevan and K. Sivakumar "A Nine-Level Inverter Topology for Medium-Voltage Induction Motor Drive With Open-End Stator Winding" IEEE 2013.

[4] J. Rodriguez, J.-S. Lai, and F. Z. Peng, "Multilevel inverters: A survey of topologies, controls, and applications," IEEE Trans. Ind. Electron., vol. 49, no. 4, pp. 724-738, Aug. 2002.

[5] G.Pandian and S. Rama Reddy "Implementation of Multilevel InverterFed Induction Motor Drive" JIT 2008.

[6] F. Khoucha and S.M. Lagoun "Symmetrical and Asymmetrical HBridge Multilevel Inverter for DTC Induction Motor Drive Automotive Applications " IEEE 2009.

[7] Malinowski, K. Gopakumar, J. Rodriguez, and M. A. Perez, "A survey on cascaded multilevel inverters," IEEE Trans. Ind. Electron., vol. 57, no. 7, pp. 2197-2206, Jul. 2010.

[8] J. Rodriguez, S. Bernet, P. K. Steimer, and I. E. Lizama, "A survey on neutral-point-clamped inverters," IEEE Trans. Ind. Electron., vol. 57, no. 7, pp. 2219-2230, Jul. 2010.

[9] S. Kouro, M. Malinowski, K. Gopakumar, J. Pou, L. G. Franquelo, B.Wu, J. Rodriguez, M. A. P'erez, and J. I. Leon, "Recent advances and industrial applications of multilevel converters," IEEE Trans. Ind. Electron., vol. 57,no. 8, pp. 2553-2580, Aug. 2010.

[10] H. Akagi, "Classification, terminology, and application of the modular Multilevel cascade converter (MMCC)," IEEE Trans. Power Electron., vol. 26, no. 11, pp. 3119-3130, Nov. 2011. 